\title{
Novos caminhos para o SUS
}

\author{
Gustavo Peixoto Soares Miguel' \\ ${ }^{1}$ Doutor em Cirurgia
}

Professor Adjunto do Departamento de Clínica Cirúrgica na

Universidade Federal do Espírito Santo (Ufes)

Diretor Científico da Associação Médica do Estado do Espítirp Santo (Ames)

O “Congresso da AMES” é o evento Médico científico mais tradicional de nosso estado. Neste ano teremos a $54^{a}$ edição do evento, onde Médicos, Estudantes de Medicina e demais profissionais de saúde terão a oportunidade de obter atualização profissional, integração e ainda renovar laços de amizade.

O tema central escolhido para o evento foi "NOVOS CAMINHOS PARA O SUS", tema atual, considerando diversas transformações que tem ocorrido na assistência médica pública em nosso país, com abertura de faculdades de Medicina e importação de Médicos sem revalidação de diplomas ${ }^{1}$. Sem perder o foco das questões técnicas e do "estado da arte", temas modernos serão abordados tais como: gestão em saúde, qualidade em saúde e segurança do paciente. Políticas de saúde, mais médicos, parcerias público-privadas e o papel das organizações sociais serão amplamente discutidos no $54^{\circ}$ Congresso da Associação Médica do Espírito Santo.

O local escolhido, Vitória Grand Hall, conta com salas adequadas para o treinamento prático em ambiente de simulação, que será oferecido em diferentes cursos. Haverá também espaço para interação com a comunidade, com o Programa P.A.R.T.Y. de prevenção de acidentes de trânsito.

Foi firmada parceria entre AMES e a Revista Brasileira de Pesquisa em Saúde - RBPS (Brazilian Journal of Health Research), Todos os trabalhos científicos aceitos para apresentação no Congresso, estão com seus resumos publicados neste suplemento especial da revista. Trabalhos selecionados foram convidados a enviar a versão integral para publicação na categoria artigo original.

A RBPS é uma revista do Instituto de Odontologia do Centro de Ciências da Saúde da Universidade Federal do Espírito Santo, com política de acesso livre para maior democratização do conhecimento. Com escopo em Saúde Coletiva, visando contribuir para a divulgação de estudos que possam ser utilizados na construção de Políticas de Saúde. Portanto, com objetivo alinhado ao tema central do congresso ${ }^{2}$.

O evento foi elaborado com objetivo de inspirar novos e antigos profissionais a rediscutir a prática Médica atual em questões clínicas, de pesquisa e as políticas de saúde. E estimular a confecção de relatórios científicos para registro da produção da ciência capixaba. O número expressivo de resumos aceitos para publicação neste suplemento, comprova o sucesso da iniciativa.

\section{REFERÊNCIAS |}

${ }^{1}$ Brasil. Decreto no 8040, de 08 de julho de 2013. Diário Oficial da República Federativa do Brasil, Brasília, 09 de jul 2013, seção 1, p.1-3.

${ }^{2}$ Santos Neto ET, A Saúde Coletiva e a Revista Brasileira de Pesquisa em Saúde. Rev. Bras. Pesq. Saúde 2012; 14(4):4-6. 